\title{
The changing shape of the dental profession
}

\author{
Peter Ward
}

Chief Executive, BDA

It has been widely reported and discussed that the shape of the dental profession is changing. This editorial seeks to begin an open discussion about the nature and implications of this change and to invite comments from members of the Association about how they feel the change has impacted upon them and what they believe needs to be done in response.

The BDA database provides a rich source of information and we can analyse our membership by a number of criteria including age, ethnicity, gender, fields of practice and indeed any combination of these. Additionally, with results from our regular surveys of members we can augment our understanding by an attitudinal overlay on the raw statistical information. As the Association grows and develops it is vital that we recognise and anticipate the changes and ensure its ongoing relevance to all members.

So what do the changes and preferences look like? Firstly, the change in gender mix that has occurred over the last forty years. BDA members who qualified 40 years ago are $85 \%$ men and 15\% women, whereas those entering the profession now are composed of $41 \%$ men and 59\% women. As a trend over time this has been a steady transition with a clear shift from a male dominated profession to one where women now represent the majority.

Ethnically there are also significant changes over time. Looking again at the cohort that qualified over 40 years ago, you will find that 65\% describe themselves of 'White - English' origin. Looking at the same characteristic in the most recent group (those aged between 17 and 25), although there is still a predominance of white, British born graduates ('White - English' and 'White - Scottish'), a significant proportion are now 'Asian/ Asian British - of Indian decent' (28\%), coupled with a growing number of those of 'Asian/Asian British - Pakistani' origin (7\%). Individual cohorts from other specific ethnic origins are still significantly under-represented within the BDA membership. For example even in the most recent cohort less than $0.4 \%$ originate from African and Caribbean communities.

So stereotypically, a dentist aged over 60 is likely to be white and male, whilst a dentist under 25 is still more likely to be white, but will now be female. The chance of that dentist being of Asian ethnicity is significantly greater than their forebears of even twenty years ago. It is unlikely in any of the cohorts that the dentist will originate from any other ethnic group.

So are these trends significant? What impacts will they have on the delivery of care and of the needs of the profession? How can we ensure that the needs of all groups are met and that individual members are served properly even if they happen to sit in a very small minority group? We must be very live to the fact that as the two populations of dentists co-exist we must seek to serve them both fully. The older group have certain needs and aspirations and whilst those at the younger end of the profession may be different we must try to serve both at the same time as well as, equally importantly, those in between.

We must also explore representation of the different groups within the BDA committee and representative structures. It is certainly the case that the shifts in populations are not reflected in the make-up and composition of the committees in the BDA. Membership of the principal committees of the BDA shows a predominance of elected representatives who are white and male. The proportions of the profession discussed above are not reflected in our structures. This begs two questions; why is this the case? and does it matter?

\section{PREPONDERANCE OF WHITE MALE COMMITTEE MEMBERS}

It might be easy to come to an initial conclusion that the preponderance of white male committee members might be to do with an 'ism', but it is important not to jump to the wrong conclusion about which one. Firstly it is important to note that the age profile of those serving on committees tends to be older (ie, where the picking pool is white and male) and the second is the fact that these are free democratic elections from the whole of the membership of individuals who declare themselves as willing to serve. So the real issue might be here that in order to establish one's credentials to a wider voting base and in order to be in a position to offer the time, might require electees to be of a certain age - which will tend to put them in the principally white male cohort.

Turning to whether it matters, makes us differentiate between 'representation' and 'representativeness'. This is to say; can someone who is different in gender, ethnic origin, age or ideology properly represent the interests of another? With a highly intelligent and articulate profession, this could bring into question something far more profound than personal characteristics - the whole issue of representational democracy. The big issue for the BDA is to make sure that our members rule the roost. In order to do that it is vital that we find ways to engage with each other to ensure that our views are heard and our needs are met. I hope that these thoughts will stimulate discussion. If we are to make our Association stronger and more relevant to us all - then please tell us what you think!

DOI: 10.1038/bdj.2007.1207 